\title{
Assessment of the use of reconstructive plate in management of mandibular defects
}

\author{
Sameh M El-Taher, MD; Asser El-Hilaly, MD; Soha F El-Mekkawy, MD; \\ Bassim M Zaki, MD; Hazem M Aly, MD \\ Plastic and Reconstructive Surgery Department, Ain Shams University, Cairo, \\ Egypt
}

\begin{abstract}
Background: The horseshoe-shaped mandible is difficult to reconstruct morphologically, and when a mandibular defect is large, graft of sufficient volume is hazardous. Although developments in micro vascular techniques and implantology have improved reconstructive surgery of the mandible to a great extent, the reconstruction of major mandibular defects, particularly of the curved anterior part, continues to pose a great challenge, and reconstructive procedures in most cases have a high rate of morbidity besides its effect on the mandible functionally and aesthetically. In this study, we will assess the extent of excision, effect of different reconstructive modalities, post operative complication rate and the effect of post-operative radiation on restoration of normal function of the mandible.

Patients and methods: this study was conducted on 60 patients, they were divided according to the site of their defect into two groups; central and lateral. Reconstruction was done with titanium reconstructive plates and either vascularized or non vascularized bone graft according to the diagnosis. We used intraoral Glasgow scale score to assess the effect of different reconstructive modalities on the functional and aesthetic outcome of the mandible.

Results: The overall complication rate was 18 patients (29.88\%) in lateral group and 10 patients $(16.66 \%)$ in central group. The most common complication was parathesia and plate exposure, No hard ware failure occurred.

Conclusion: the size of the defect, mode of reconstruction and post operative irradiation can affect the functional and aesthetic outcome.
\end{abstract}

\section{Introduction:}

Mandible reconstruction is both a functional and aesthetic procedure. The mandible is involved in mastication, speech, appearance, expression, and sensation. So the goals of mandibular reconstruction are to achieve primary wound healing, early functional oral rehabilitation, and restoration of the patient's body image. Reconstruction of the mandible, particularly the segmental defect, has historically been one of the most difficult challenges faced by plastic surgeons.1,2
Mandibular reconstruction may be indicated for defects from oncologic resection and traumatic injuries. The evolution of microsurgery has completely changed our expectations and approach to mandible reconstruction. Improvement in microsurgical techniques, refinement of composite tissue donor sites, use of rigid fixation systems, and osteointegrated dental implants has revolutionized reconstruction of oromandibular defects. Functional and aesthetic rehabilitation of the mandibulectomy patient is now possible in nearly all cases. ${ }^{3}$ 


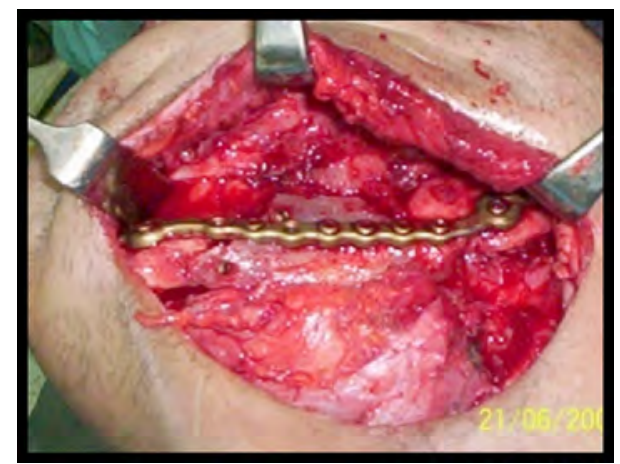

(A)

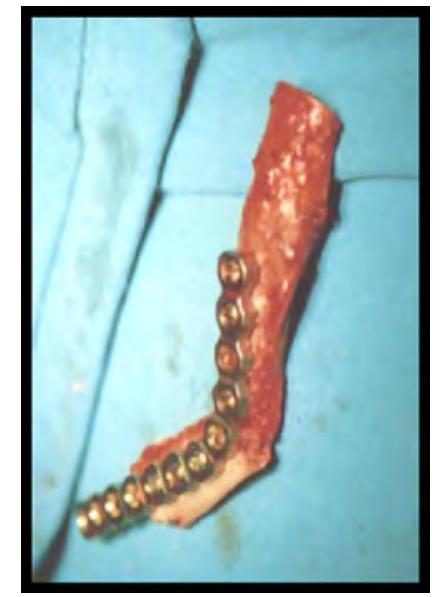

(B)

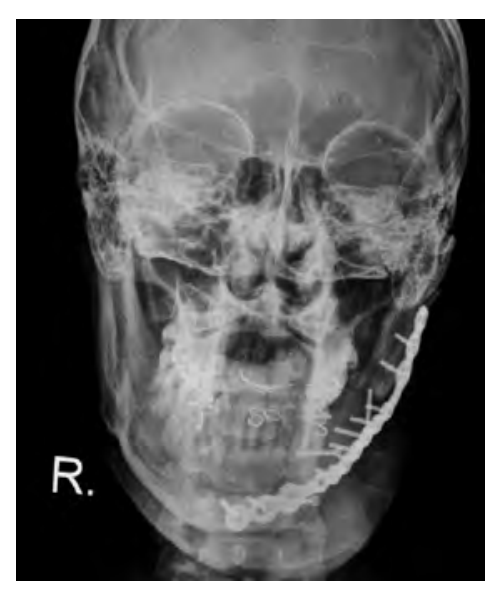

$(C)$

Figure (1): Shows a case with mandibular tumor reconstructed by titanium reconstructive plate; (A) Intra-operative application of the plate, (B) Plate and the bone graft, (C) Post operative $x$-ray for the mandible.

The size and location of the mandibular defect influences the surgeon's reconstructive choice. Large-sized defects (such as hemimandibular segments) or those defects that encompass the entire symphysis may favor a vascularized reconstruction to enhance bone healing and maintenance of graft volume. Smaller sized defects involving the ramus or body, or those that are limited to the condylar- ramus segment may be better suited for nonvascularized bony reconstruction..$^{4,5}$ A good composite classification system for mandibular defects has been proposed by Boyd 1 and presents a good approach to reconstructive planning based on the location of the missing bone segment and accompanying soft tissue deficit. 6
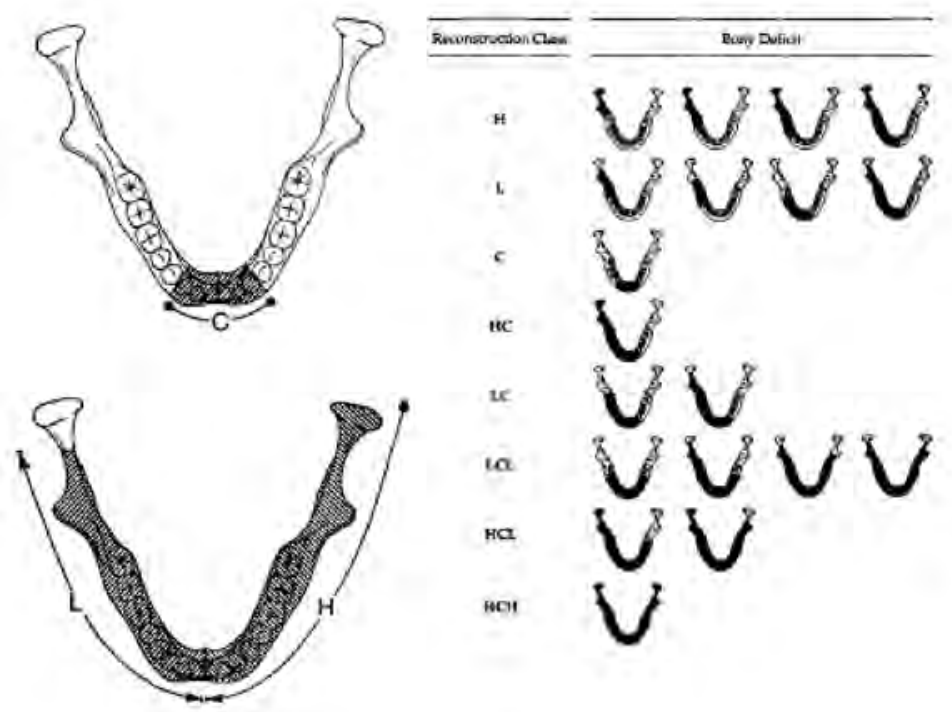

Figure (2): The Boyd (HCL) classification system of mandibular defects. $\boldsymbol{H}$ represents a lateral segment of any length containing a condyle and not crossing the symphyseal midline. $\boldsymbol{L}$ represents the same type defects but without the condylar segment. $C$ represents the bony segment between the mental foramen. The qualifying letters of $\boldsymbol{o}, \boldsymbol{m}, \mathbf{s}$, and $\mathbf{m s}$ are used to denote bone only or accompanying mucosa, skin, and skin and mucosal soft tissue defects. This makes eight possibilities for the bony defect and four for soft tissue. 
Reconstruction of the mandible necessitates two basic components: An autogenous bone graft source and a stable method of graft stabilization. ${ }^{7,8}$ Large reconstruction plates ( $2.0 \mathrm{~mm}$ to $3.5 \mathrm{~mm}$ in thickness) of varying metal compositions (epescially the titanium made plates) and malleability are one of the most popular methods of stabilizing the mandibular segments and securing the bone graft, while the created defects may require bony restoration, soft tissue replacement, or both. 9,10

The evolution of internal fixation was aided by the discovery of biocompatible materials that resisted corrosion, such as vitallium and titanium. Currently, titanium is the metal of choice for fixation plates, mainly because of its high biocompability, ease of manipulation, and the potential for no second surgery. Titanium plates provide rigid fixation for mandibular fractures. They can be easily adapted to the bone curvature and require only a simple surgical procedure. ${ }^{11-13}$
The adult human man may generate between 300 and $400 \mathrm{~N}$ maximal bite force. This magnitude is reduced when a fracture has occurred in the masticatory system for this reason, when attempting to evaluate the biomechanics of various fixation techniques, it is important to consider clinically relevant parameters to provide meaningful information to the clinician. In the literature, there are only a few investigations that evaluate the bite forces of the postsurgical population. Ellis et al.1995 found that the bite forces in the acute postoperative period of the patients treated for mandibular angle fractures and orthognathic surgery patients are much less than it is recorded later in the postoperative period or in the nonoperated population. Based on the studies of bite force in postoperative patients, Hidalgo et al. $2002^{14,15}$ postulated that meaningful mechanical behavior would be obtained within the ranges of 0 to $100 \mathrm{~N}$ ranges for incisal edge loading and 0 to $200 \mathrm{~N}$ for contralateral molar loading, in their biomechanical evaluation of mandibular angle fracture plating techniques with synthetic polyurethane replica mandibles.

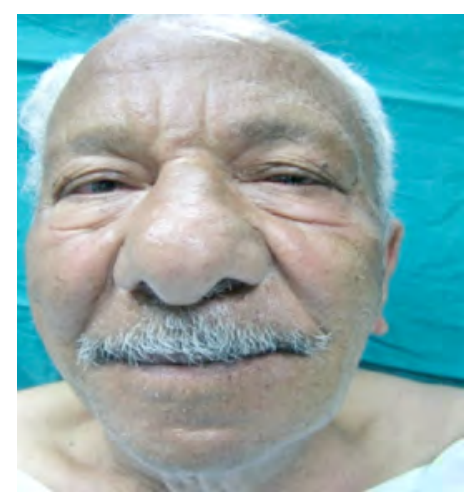

(A)

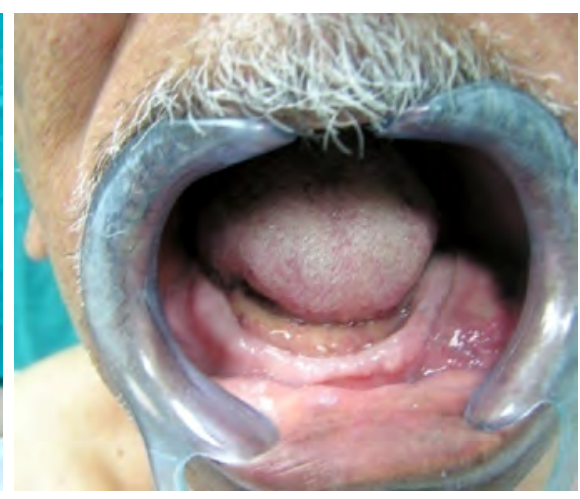

(B)

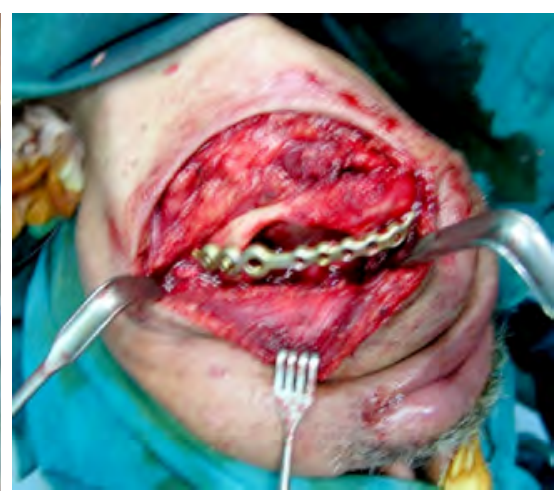

(C)

Figure (3): Shows a case with mandibular osteomyelitis reconstructed by titanium reconstructive plate; (A) Preoperative front view of the patient, (B) Intra oral view of the mandible, $(C)$ Intraoperative application of the plate. 
Malleable metal reconstruction plates were developed for use in trauma and in segmental mandibulectomy reconstructions. The technique is widely used due to ease of application, rigid fixation, and lack of donor site. However, this approach suffers from a lack of long-term reliability because of stresses on the mandibular fragments leading to screw loosening, plate fatigue, and fracture. ${ }^{12}$ Inadequate soft tissue coverage, particularly in the radiated patient, results in plate extrusion in many anterior defects. Reconstructions by plates only are contraindicated in this location. Laterally placed plates are somewhat better. Reconstruction with a titanium metal plate may be preferable in poor prognosis patients without a prior history of radiation if limited to short, lateral defects with good soft tissue coverage. In such instances, metal plate reconstructions are usually covered with local soft tissue flaps. ${ }^{16}$

So restoration of bony continuity of the mandible contributes to functional outcome as well as improved aesthetics. A mandibular profile is important in facial symmetry and balance. A proper mandibular reconstruction maintains height, width, and projection of the lower one third of the face. . $^{3,17}$

Unreconstructed anterior mandible defects result in posterior and inferior chin displacement, the "Andy Gump" deformity. Loss of continuity in the lateral or posterior segments results in cheek contour deformity and deviation of the symphysis from the midline when the mouth is open. ${ }^{1}$

Bony reconstruction of the mandible is also important for normal function. Central defects result in loss of support for the hyomandibular complex, contributing to aspiration, dysphagia, oral incompetence, and difficulty with mastication. Lateral defects result in upward and lateral displacement of the mandibular remnants due to uninhibited influence of the opposite intact muscles of mastication, creating difficulty with bimaxillary relationships and occlusion. Eventually, bony reconstruction can be nonvascularized ${ }^{3}$ or vascularized bone grafts $10,18,19$ with or without free tissue transfer e.g. fibula, ${ }^{5,20-22}$ radius, ${ }^{23}$ scapula and iliac bone. 24

As the technique implies, any method of nonvascularized reconstruction relies upon the surrounding soft tissue and adjoining mandibular ends for a sufficient blood supply to permit angiogenesis into the graft and maintain a stable inner mucosal and outer cutaneous cover therefore, any pathological condition that compromises the periosteal or subcutaneous vasculature is a contraindication to these techniques, including the following: radiation, either pre or postoperatively; extensive fibrosis caused by previous surgeries, infections, or chronic contamination; or inflow insufficiency caused by resection or embolization of external carotid branches supplying the involved region. ${ }^{25}$

Non vascularized bone grafts from various donor sites (iliac crest, rib, calvarium) may be appropriate in selected cases. Segmental mandibulectomy reconstruction using non vascularized bone is largely limited to small defects with excellent soft tissue coverage, short $(<5 \mathrm{~cm})$ lateral segment defects in wounds that have not been or will not be radiated. Even for many of these patients, micro vascular transfer of vascularized bone is often preferable. Other indications for nonvascularized reconstruction include the treatment of mandibular fracture non unions and resection of benign tumors with good skin coverage. ${ }^{4,9}$ 


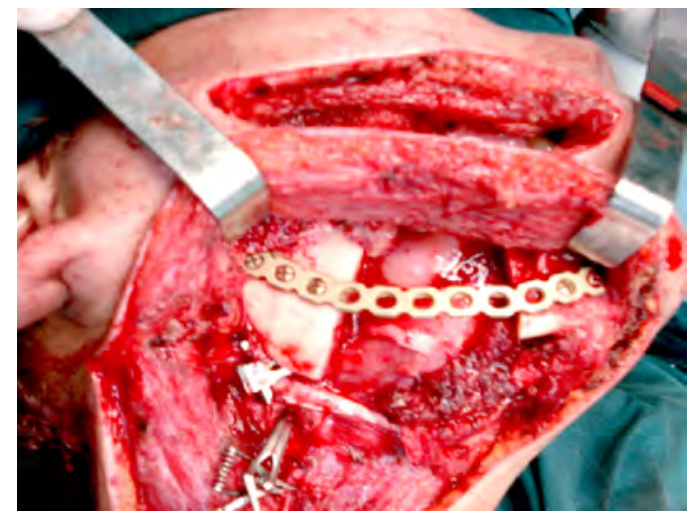

(A)

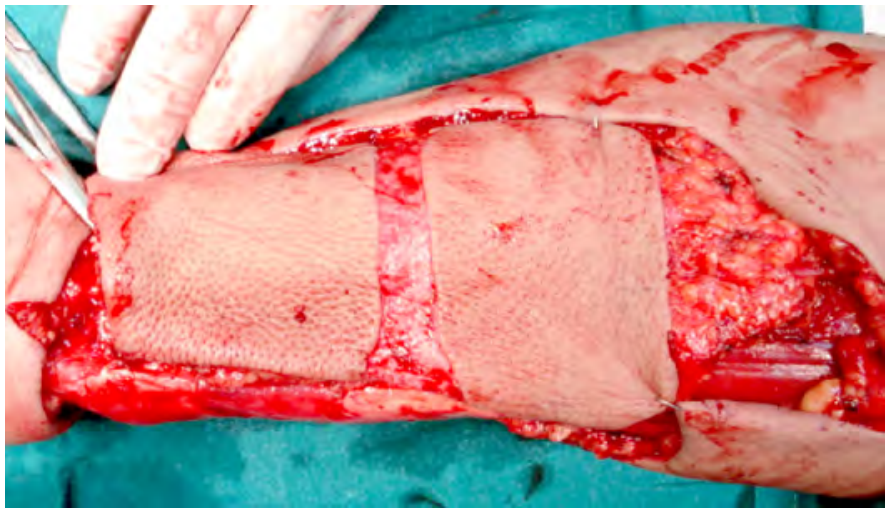

(B)

Figure (4): Shows a case with mandibular tumor reconstructed by radial forearm flap; (A) intra-operative view of the defect with the reconstructive plate, $(B)$ Design of the radial forearm free flap.

The choice of the free flap used for reconstruction of the mandible is determined therefore by the characteristics of the defect. The free vascularised fibula flap has become recognised as a useful technique for larger bony defects, since Taylor reported the first successful case in $1975 .{ }^{26}$ When Hidalgo first used the free vascularized flap in 1989 as a new method for reconstruction of the mandible, it has become an effective and safe procedure, ${ }^{27}$ giving excellent results both functionally and aesthetically. Other advantages are: double periosteal and medullary blood supply allowing multiple osteotomies and correct contouring, an adequate pedicle length and the low donor site morbidity. ${ }^{28-31}$

On the other hand, adequate soft tissue reconstruction is an important adjunct to bony repair. Primary soft tissue healing is essential to prevent the complications of infection, fistula, intraoral bone or hardware exposure, and major vessel erosion. ${ }^{32,33}$ The degree of soft tissue disruption, particularly of the tongue and oropharynx, will ultimately determine the functional outcome. Improper or inadequate replacement of soft tissue deficits predisposes to wound healing problems, particularly when radiation is part of the therapy. ${ }^{5}$

So in this series, we monitored the extent of excision, effect of different reconstructive modalities, post operative complication rate and the effect of post-operative radiation on restoration of normal function of the mandible.

\section{Materials and methods:}

This study was done in the Plastic and Reconstructive Surgery Department, Ain Shams University Hospitals between March 2005 and July 2008. Sixty patients were enrolled in this study aging from 20 to 76 years (mean age 44.3 years) 34 were males and 26 were females. 20 smokers, 13 hypertensives and 11 were diabetics.

They were divided according to the site of the mandiblular defect into two groups; GroupI (Central defects): It included thirty patients where in 16 patients the central defect was due to trauma (comminuted fractures), the other 14 were due to tumors ( 8 cases were concised to the bone and 6 cases extended to involve the surrounding soft tissues). 24 cases of them needed reconstruction by bone graft only while in the remaining 6 we used bone and soft tissue reconstruction as the excision included large soft tissue areas and those patients needed radiotherapy later on. GroupII (Lateral defects): It included thirty patients where in 17 patients the lateral defect was due to trauma (comminuted fractures); the other 13 were due to tumor ( 9 cases were concise to the bone and 4 cases extended to involve the surrounding soft tissues). 26 cases of them needed reconstruction by bone graft only while in the remaining 4 we used bone and soft tissue reconstruction due to the nature of excision involving soft tissue and the need for post operative radiation. 


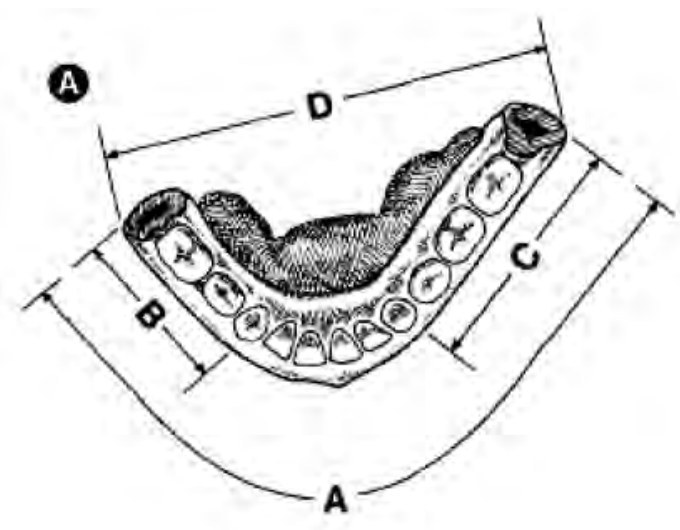

(A)

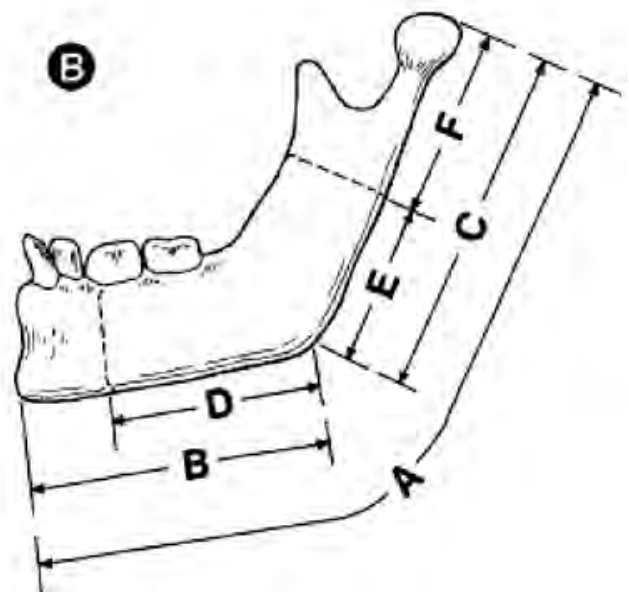

(B)

Figure (5): (A) A typical anterior resection specimen with key measurements indicated which are useful for reference during the graft-shaping process. Total specimen length is indicated by $A$, body segment length; by $s$ and $c$, and body segment splay by $D$. (B) A typical lateral specimen is shown with key measurements indicated by $A-F$. Total specimen length is represented by $A$, total body length by $B$, total posterior height by $c$, body length from the angle to the osteotomy site which will impart curve to the body by $D$, and the ramus and condyle lengths by E and $F .34,35$

All patients with composite or extensive composite oromandibular defects underwent reconstruction with Titanium 3-DBRP (3-dimensional bendable reconstruction plate). The excision of the mandible ranged from 6 $12 \mathrm{~cm}$ in GroupI (Central), while in GroupII (Lateral) it ranged from $5-13 \mathrm{~cm}$. All tumor cases had presurgery incisional biopsy to determine its degree of oncogenesity. We assessed the extent of excision and effect of different reconstructive modalities on restoration of normal action of the mandible by using either: Functional parameters - which included assessment of speech, chewing, swallowing, occlusion, competence of oral sphincter and tempro-mandibular joint functions; or: Aesthetic parameters - which included patient and doctor satisfaction, facial expression, contour and projection of the mandible.

Speech, chewing and swallowing - of the functional parameters - were monitored for an average follow up period of 18 months (range from 6 to 24 months) where patients were checked bimonthly and the results were checked clinically with each follow-up visit. Assessment of speech quality was done by Functional Intraoral Glasgow Scale Selfquestionnaire which is an ordinal five-grade scale questionnaire, with high values indicating good speech Table(1), and Conversational Understandability Test where voiceless fricative segments, $|\mathrm{s}|,|\mathrm{sh}|,|\mathrm{f}|$, and $|\mathrm{th}|$, were used for analysis. 36,37

The occlusion, contour and mandibular projection were assessed by X-rays which assess the relation of the mandible to the other facial bones.

\section{Strategy of reconstruction:}

The reconstructive techniques used differed according to the size, site and the component of the mandible defect. The reconstructive plate was used alone with defects $-8 \mathrm{~cm}$ without soft tissue loss, and in combination with either non-vascularizd or vascularizd bone graft with defects $>8 \mathrm{~cm}$. On the other hand, it was used with local, distant or free flap in cases with extensive soft tissue excision with concomitant post operative radiotherapy. 


\section{Results:}

The study conducted on these patients had four main items of assessment; the excision, reconstruction modality, post operative complication rate and the effect of postoperative radiation on the functional outcome of the mandible.

In all the 33 traumatic patients $(55 \%)$ debridement of devitalized non fixable bone fragments was done. While in 8 patients $(13.33 \%)$ soft tissue was also debrided due to severe necrosis of tissues. In the remaining 27

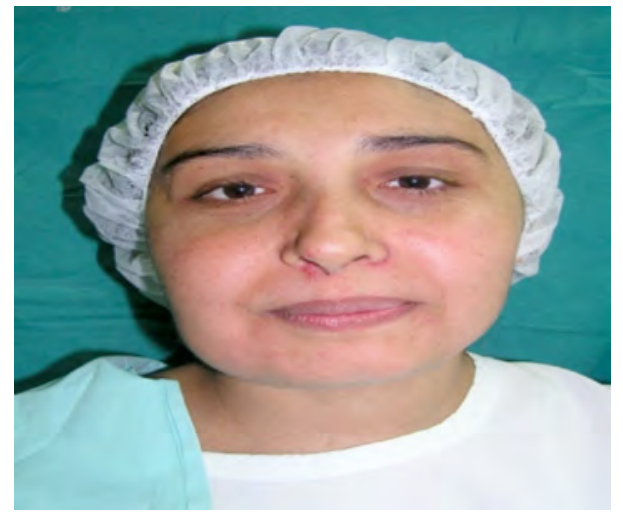

(A)

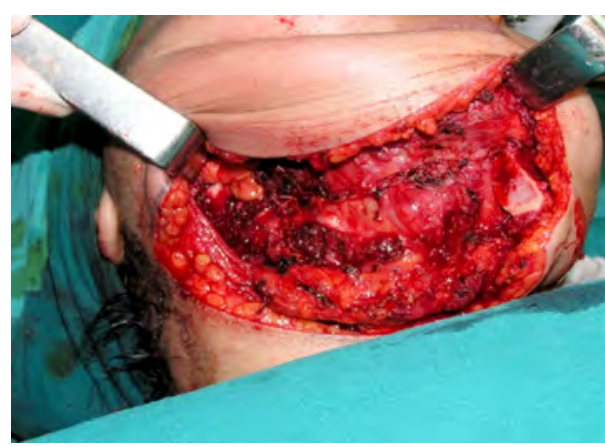

(C)

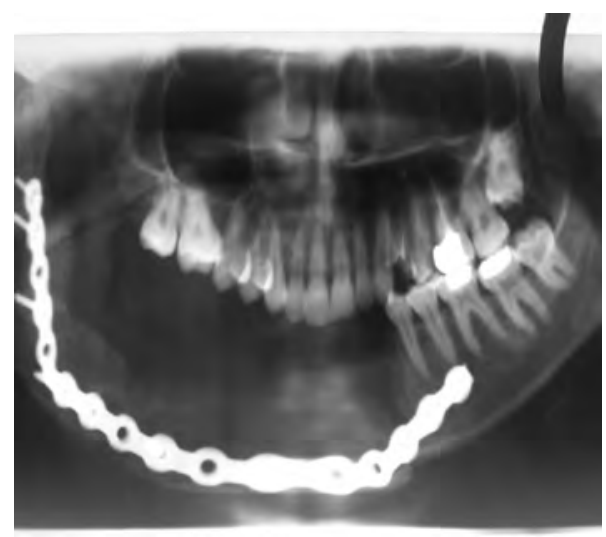

(E) patients $(45 \%)$ excision of the bone with or without soft tissue was done according to previous histopathological examination (benign tumors (17 patients $28.22 \%$ ); excision of the tumor only while in the malignant sarcoma or carcinoma (10 patients $16.66 \%$ ); excision of the adjacent bone and soft tissue is done with expected safety margin). Highly selective lymhadenectomy was done in 6 patients $(9.96 \%)$ who were previously assessed by using both; sentinel lymph node biopsy and soft tissue MRI scan.

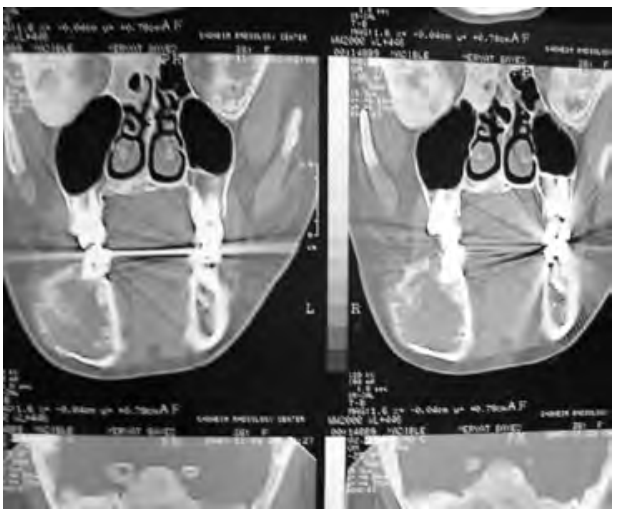

(B)

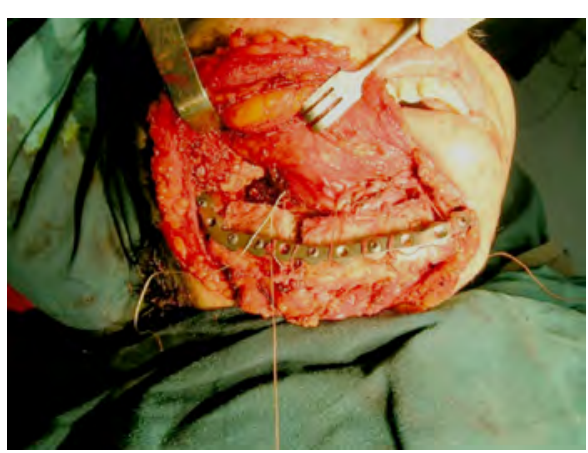

(D)

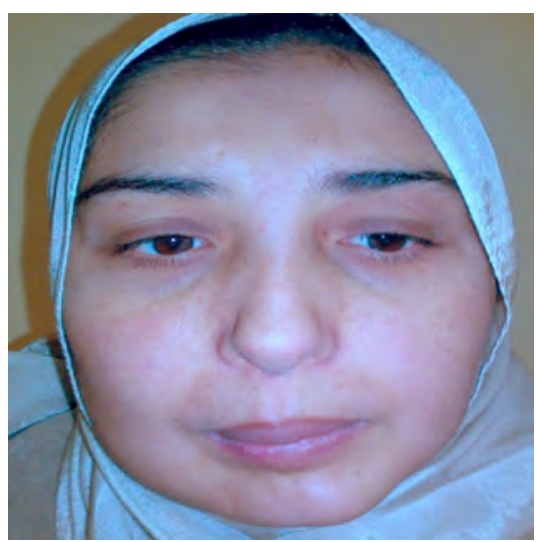

$(F)$

Figure (6): Shows a case with adamantinoma of the mandible; (A) Pre-operative view, (B) CT scan coronal cuts showing the tumor, $(C)$ Intra- operative view of the defect, $(D)$ Intra-operative view of the defect with the reconstructive plate, (E) Post-operative panorama of the mandible showing the reconstructive plate, $(F) 6$ ms postoperatively. 
Then these defects were reconstructed according to bone defect, soft tissue defect, anatomical area of the mandible, age of the patient and fitness for long period of anesthesia. 4 patients $(6.64 \%)$ from the lateral group who were poor surgical candidates (i.e. old patients), edentulous, small bone defects $-3 \mathrm{~cm}$ and posterior benign small tumors were reconstructed by using Titanium 3-DBRP. We did not use the plate alone in the central defects.

Forty Patients $(66.66 \%)$ who were fit for surgery without soft tissue affection, with large lateral defects not exceeding $8 \mathrm{~cm}$ (12 patients $19.92 \%$ post traumatic and 8 patients $13.33 \%$ with benign tumors), any central defect (15 patients $24.9 \%$ post traumatic and 5 patients $8.3 \%$ with benign tumors) were reconstructed by titanium reconstruction plate together with non vascularized bone (iliac bone, costochondral and calvarial bone graft).

While in 9 patients $(14.92 \%)$ with defects more than $8 \mathrm{~cm}$ without soft tissue affection (lateral group: 2 patients $3.32 \%$ post traumatic and 2 patients $3.32 \%$ with benign tumors), while in (central group: 2 patients $3.32 \%$ post traumatic and 3 patients $5 \%$ with benign tumors) were reconstructed by titanium reconstruction plate together with vascularized free bone graft (free fibula).

In severe bone defects ( 7 patients $11.62 \%$ ) either central (5 patients $8.3 \%$ ) or lateral (2 patients $3.32 \%$ ) with extensive tissue loss or excision reaching to the surrounding structures or the floor of the mouth reconstruction was done by titanium reconstruction plate together with vascularized bone and soft tissue transfer (latissimus muscle flap, radial forearm and free fibula with adjacent muscles).

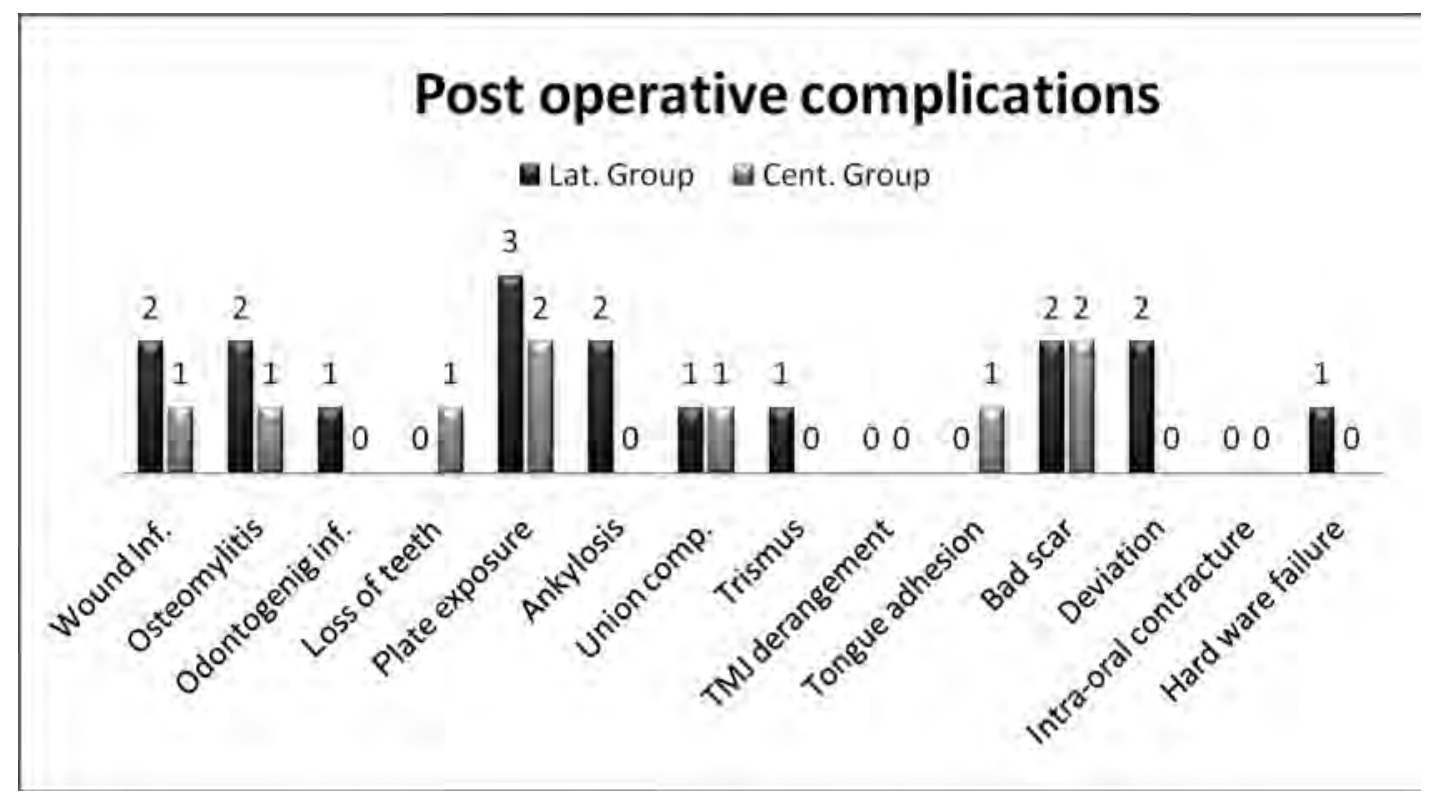

Chart (1): Showing the post operative complication rates in both groups.

The overall complication rate was 26 (43.13\%) out of 60 patients (17 patient $28.22 \%$ in lateral group and 9 patients $14.94 \%$ in central group). The most common complication was plate exposure in 5 patients $(8.3 \%)$. On the other hand there was only 1 case of hard wares failure occurred in this thesis. Ten of the patients underwent minor operations, such as removal of the exposed reconstruction plate
(3 patients $4.98 \%$ ), revision of the bad scar (4 patients $6.64 \%$ ), and release of tongue adhesions (1 patient $1.66 \%$ ). The decision to perform a secondary procedure was based on the general health of the patient, the extent of local disease, and the severity of the complications. The effect of different reconstructive modalities on the mandible function was listed as follows: 
Table (1):

\begin{tabular}{|c|c|c|c|}
\hline & & Condition & Score \\
\hline \multirow{22}{*}{$\begin{array}{l}\text { Functional } \\
\text { Intra-oral Scale }\end{array}$} & \multirow{5}{*}{ Speech } & Always understandable & 5 \\
\hline & & Needing sometimes repetitions & 4 \\
\hline & & Needing many times repetitions & 3 \\
\hline & & Understandable only by relatives & 2 \\
\hline & & Incomprehensible & 1 \\
\hline & \multirow{5}{*}{ Chewing } & Any food without difficulty & 5 \\
\hline & & Solid food with difficulty & 4 \\
\hline & & Semisolid food without difficulty & 3 \\
\hline & & Semisolid food with difficulty & 2 \\
\hline & & Chewing impossible & 1 \\
\hline & \multirow{5}{*}{ Swallowing } & Any food without difficulty & 5 \\
\hline & & Solid food with difficulty & 4 \\
\hline & & Semisolid food only & 3 \\
\hline & & Liquid only & 2 \\
\hline & & Swallowing impossible & 1 \\
\hline & \multirow{4}{*}{ Sphincter } & Air Tight & 4 \\
\hline & & Water Tight (Drooling of saliva) & 3 \\
\hline & & $\begin{array}{l}\text { Solid Tight } \\
\end{array}$ & 2 \\
\hline & & Incompetent & 1 \\
\hline & \multirow{3}{*}{ Occlusion } & Good & 4 \\
\hline & & Fair & 2 \\
\hline & & Poor & 1 \\
\hline \multirow{18}{*}{$\begin{array}{l}\text { Aesthetic } \\
\text { Intra-oral Scale }\end{array}$} & \multirow{4}{*}{$\begin{array}{c}\text { Patient } \\
\text { satisfaction }\end{array}$} & Excellent & 4 \\
\hline & & Good & 3 \\
\hline & & Fair & 2 \\
\hline & & Poor & 1 \\
\hline & \multirow{4}{*}{$\begin{array}{l}\text { Doctor } \\
\text { satisfaction }\end{array}$} & Excellent & 4 \\
\hline & & Good & 3 \\
\hline & & Fair & 2 \\
\hline & & Poor & 1 \\
\hline & \multirow{4}{*}{ Excision } & Bone only - $3 \mathrm{~cm}$ & 4 \\
\hline & & Bone only $>3 \mathrm{~cm}$ & 3 \\
\hline & & Bone and adjacent soft tissue & 2 \\
\hline & & Bone and soft tissue extending to oral cavity & 1 \\
\hline & \multirow{3}{*}{$\begin{array}{l}\text { Projection } \\
\text { of mandible }\end{array}$} & Good & 3 \\
\hline & & Fair & 2 \\
\hline & & Poor & 1 \\
\hline & \multirow{3}{*}{ Cosmesis } & $\begin{array}{c}\text { Normal appearance with symmetry of } \\
\text { lower jaw and the chin (Good) }\end{array}$ & 3 \\
\hline & & $\begin{array}{c}\text { Clear defect but with symmetry of lower } \\
\text { jaw and the chin (Acceptable) }\end{array}$ & 2 \\
\hline & & $\begin{array}{l}\text { Significant defect but with asymmetry of } \\
\text { lower jaw and the chin (Un-acceptable) }\end{array}$ & 1 \\
\hline & & Total Score & 40 \\
\hline
\end{tabular}


Regarding the functional and aesthetic outcome of the mandible we assessed the effect of different reconstructive modalities by using intraoral Glasgow scale score. Each parameter was given a point from 1 to 5 according to the condition found. Total score was then calculated and was correlated with a reference range. We found that:

- 33 - 40----> Excellent, it was found in 18 patients $(29.88 \%)$, and they were treated with titanium reconstructive plate together with non-vascularized bone graft.

- 26 - 32 --> Good, it was found in 26 patients $(43.16 \%), 20$ patients were treated with titanium reconstructive plate together with non-vascularized bone graft, 2 patients were treated with titanium reconstructive plate together with vascularized bone graft, 2 patients were treated with titanium reconstructive plate together with vascularized bone graft and soft tissue and 2 patients were treated with titanium reconstructive plate alone as they were fit for surgery.

- 18 - 25 ---> Fair, it was found in 13 patients (21.58\%), 7 patients were treated with titanium reconstructive plate together with vascularized bone graft, 4 patients were treated with titanium reconstructive plate together with vascularized bone graft and soft tissue and 2 patients were treated with titanium reconstructive plate alone as they were not fit for surgery.

- 10 - 17 ---> Poor, it was found in 3 patients $(4.98 \%)$, they were treated with titanium reconstructive plate together with vascularized bone graft and soft tissue.

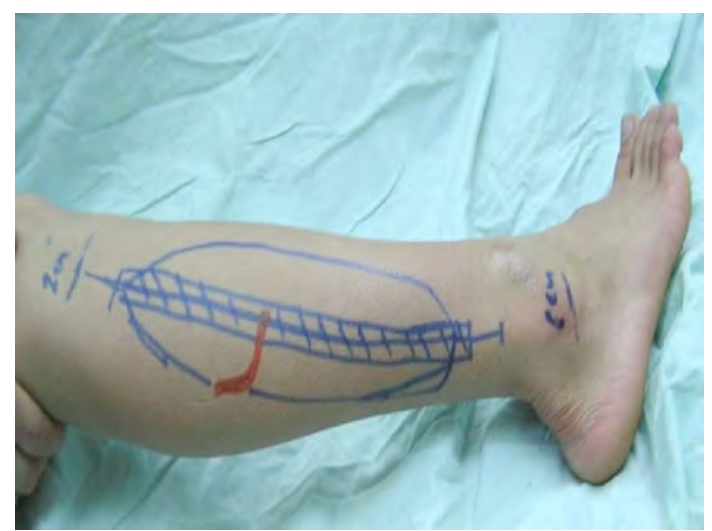

(B)

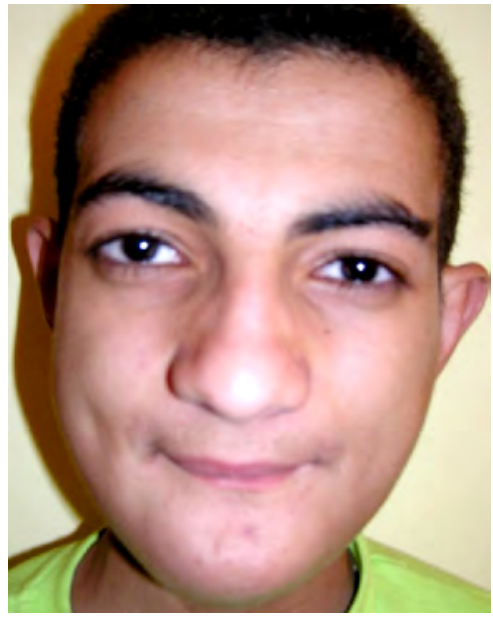

(D)

Figure (7): Shows a case with Giant cell tumor of the mandible; (A) Pre-operative view, (B) Design of the free fibula flap, $(C)$ Intra-operative view of the defect with the reconstructive plate, (D) 6 ms postoperatively. 
Ten patients received postoperative external beam radiotherapy, with a mean dose of 5873 cGy (range, 4200 to $6600 \mathrm{cGy}$ ) to the tumor site and neck. They received postoperative radiotherapy from 4 to 6 weeks after surgery. The titanium plate and the mandibular bone were included in the radiotherapy fields in all irradiated patients.

\section{Discussion:}

It is essential to maintain the threedimensional anatomical relationships (i.e. the mandibular contour and continuity) in reconstructing the oromandibular defects, for functional and cosmetic reasons. Important physiologic functions such as deglutition, mastication, articulation and oral competence can be affected severely if these anatomical relationships were not preserved.2,5

Internal fixation with plates and screws aims to maintain and to protect the shape of the mandible (whether in reduction of the fracture or tumor resection). This is a mechanical function of force transmission. Therefore, the plate must be firmly fixed by the screws onto the bone. In order to fulfill this function of mandibular segement stabilization, two mechanisms might be involved: The bending stiffness of the screws and the friction between plate and bone. ${ }^{3}$

The compression plates require screws with spherical counter sink in order to allow free inclination of the screw. The advantage of these screws is the possibility to use the plate screw for the fixation of the fracture. However, the structural rigidity is strongly reduced when compared to screws firmly oriented within the plate. This is due to the fact that the bending stiffness of the screws is rather moderate, and does not allow forces larger than $1200 \mathrm{~N}$ to be sustained. The plate is firmly pressed onto the bone when the screws are tightened.2,16

In this study all sixty patients underwent reconstruction by using Titanum metal plate due to its great advantages and biocompatibility over both malleable or stainless steel plate. It is safe, with rapid application, good cosmetic result and a relatively low rate of plate removal in our patients. It also produces small amount of callus in comparison to the stainless steel plates which allows better radiological assessment of the fracture union. Loosening of the plate was observed in 1 patient and no patient experienced plate fracture.

In our study reconstruction by plate alone without bone was used in four patients who were poor surgical candidates, palliative excision particularly edentulous patients with only small posterior mandibulectomy defects.

In our study bone defects up to $8 \mathrm{~cm}$ can be reconstructed by bone graft with the use of weight bearing mandibular reconstruction plate, Iliac bone was used for body reconstruction in 17 patients while rib or costochondral graft was used for the ramus reconstruction in 14 patient and another 2 patient complicated by TMJ ankylosis. The remaining 9 patients who were treated by non vascularized bone, the source of the donor bone was obtained from calvarial bone due to associated head and neck injuries. All previous patients were traumatic or benign tumors, so their was no need for postoperative radiotherapy.

In this series, 13 cases were done by using vascularzied free flap among which the free fibula took the upper hand (in 7 patients and in secondary revision for 2 patients) due to its advantages and less donor site morbidity. Although the iliac crest and radius have their uses, they have been kept as the second choice in those patients for whom the fibula is not a reconstructive option. The radial forearm flap, though having many desirable characteristics, is associated with an unacceptably high rate of fracture of the bone at the donor site (in 2 patients where a skin paddle was needed to cover facial skin defect due to its pliability and skin color match). Latissimus dorsi either pedicled (in 3 patients) or free flap (in 2 patients) was used in reconstruction of defect after ablation of malignant mandibular tumor with extensive soft tissue affection. It was also used after osteoradionecrosis in one patient. 
Table: Characteristics of the commonly used free flaps for mandible reconstruction

\begin{tabular}{lcccc}
\hline Free flap & Bone quality & Skin paddle & Vascular supply & Donor site morbídity \\
\hline Radial forearm & + & ++++ & ++++ & ++++ \\
Scapular & ++ & +++ & +++ & ++ \\
Fibular & ++++ & +++ & +++ & ++ \\
Iliac crest & +++ & + & ++ & ++++ \\
\hline
\end{tabular}

In this series, a high late complication rate was observed when composite or extensive composite oromandibular defects were reconstructed with soft-tissue free flaps and reconstruction plates. The most frequently observed complication in this series was reconstruction of plate exposure. Although only 5 patients with reconstruction plate exposure underwent reconstruction with a fibula osteoseptocutaneous flap. The plate exposure rate was $8.3 \%$ (5 of 60 cases), and the overall complication rate was $43.13 \%$ (26 of 60 cases).

In addition, a gradually increasing number of complications among the rest of the patients who are still under observation can be expected. This is an important consideration after these types of reconstructions of the oromandibular area, because the soft-tissue flap gradually shrinks, local continuous movement of the mandible distorts the plate, and screws loosen with time. Therefore, complications should be expected and these patients should be monitored regularly. $25,32,33$

Mechanisms of intraoral and extraoral plate exposure have been proposed by Boyd et al. and Blackwell et al., respectively. Boyd et al. ${ }^{5}$ attributed intraoral plate exposure among patients with anterior mandibulectomy defects to disconnection of all mouth-opening muscles, denervation of lower lip musculature, and ptosis of the lower lip. Boyd et al. reported a plate removal rate of 21 percent in their series and also noted that the cosmetic results for the patients in that group were evaluated as unacceptable. However, external plate exposure in lateral mandibulectomy defects results from wound contracture. The plate produces pressure on the overlying skin and, with time, results in inevitable pressure necrosis of the skin. ${ }^{38}$

Paresthesia of the lip and chin secondary to trauma to the inferior alveolar nerve is often seen with fractures through the intra bony course of the nerve (angle and body regions). Paresthesia may also result from treatment by stretching or avulsing the mental nerve during transoral approaches or violation of the nerve with drill holes and screws. However, lip and chin sensation (sometimes in altered form) usually returns within 6 to 24 months after the fracture. 25,38

TMJ ankylosis was also noted in 2 patients in our series where the treatment of ankylosis varies from interpositional arthroplasty and gap arthroplasty to costochondral grafting or total joint prosthesis. The common method for success is vigorous physical therapy to maintain joint function after surgical correction. Without therapy, any correction fails. It should be noted that bony ankylosis correction generally achieves long-term inter incisal opening of 25 to $28 \mathrm{~mm} .{ }^{39}$

Shibahara et al reported that the rate of titanium plate fracture was $8.3 \%(4 / 48)^{13}$ and suggested that new ways of bending the plates are needed to decrease the stress applied to them, that the radiation dose should not exceed $30 \mathrm{~Gy}$, and the plates should be sufficiently covered with soft tissue. ${ }^{40,41}$ But 30 Gy is not an adequate dose to irradiate subclinical disease in the adjuvant setting. Irish et al. reported on 51 patients who underwent resection and titanium plate reconstruction and had a $24 \%$ rate of plate failure. ${ }^{13}$ The incidence of plate failure was higher for patients who had excessive mandibular tissue resection. In contrast to other reports, the rate of plate failure was not influenced by the addition of RT. ${ }^{42,43}$ We observed that flap reconstruction is associated with a lower risk of plate failure and have previously found that these flaps tolerate postoperative RT well. When the thickness of soft tissue over the plate is $5 \mathrm{~mm}$, the risk of plate exposure probably increases. Thus, the quantity and thickness of tissue necessary for reconstruction of the soft tissue 
defect should be precisely estimated during the operation that occurred in two patients $(3.33 \%)$ who later on reconstructed by free latissimus muscle flap.

In this study our main aim was the restoration of bony continuity of the mandible contributing to functional outcome as well as improved aesthetics. Several studies aiming to evaluate functional and esthetic outcome after reconstruction of mandibular defects which in most cases only a correlation to broad factors could be statistically demonstrated.

We investigated speech, mastication and swallowing by the original two subjective assessment methods (Conversational Understandability Test and Functional Intraoral Glasgow Scale), 36,37 we added some parametric measures to the previous scale to cover almost all functional and aesthetic outcomes.We found that "Excellent" result (patient got from 33 - 40), was found in 18 patients treated with titanium reconstructive plate together with non-vascularized bone graft in small defects - $5 \mathrm{~cm}$ without affecting the adjacent muscle which are responsible for chewing and mastication, in these patient the injury did not involve the floor of the mouth or the oral cavity. Thus the reconstruction was restricted to the bone only.

The 3 patients who underwent reconstruction by plate and free bone and soft tissue were considered the worst patients as regard both function and aesthetic outcome; their score did not exceed 17. This can be explained by the extensive trauma or tumor which affect not only the mandibular bone but also extend to involve the muscle and the oral cavity. Other possible cause for these patients to have this worst score was due to post operative irradiation with affection on the irradiated part. On the other hand, the scores of the rest of the patients ranged from good to fair that was according to the size of the defect resulted after tissue debridement following trauma or tumor excision, reconstructive modalities and post operative irradiation.

\section{Conclusion:}

From this study, we can conclude that the size of the defect, mode of reconstruction and post operative irradiation can affect the functional and aesthetic outcome. Smaller defects $-8 \mathrm{~cm}$ managed with good aligned titanium reconstructive plate together with vascularized or non vascularized bone graft have good and acceptable outcome. While for patients with extensive tissue loss (malignant tumor), reconstruction by any option still had a poor outcome which needs further study to solve this problem.

\section{Conflict of interest statement:}

The authors listed on this paper state that there are no financial and personal relationships and no conflict of interest.

\section{References:}

1- Chacon GE, Larsen PE: Principles of management of mandibular fractures. In: Peterson's principles of oral and maxillofacial surgery. Miloro M, Ghali GE, Larsen PE, Waite PD (Editors); Hamilton: BC Decker (Publisher); 2nd edn. 2004; p. 410.

2- Wagner JD: Preoperative assessment and preparation for mandible reconstruction. Operative Techniques in Plastic and Reconstructive Surgery 1996; 3(4): 217 225.

3- Mehta RP, Deschler DG: Mandibular reconstruction: An analysis of different techniques. Curr Opin Otolaryngol Head Neck Surg 2004; 12: 288-293.

4- El-Shahat A, Maher H, El-Badawy A: An algorithm for oro-mandibular reconstruction. Egypt J Plast Reconstr Surg 2004; 28(2): 133-139.

5- Boyd JB, Morris S, Rosen IB, et al: The through-and-through oromandibular defect: Rationale for aggressive reconstruction. Plast Reconstr Surg 1994; 93: 44-53.

6- Boyd JB, Gullane PJ, Rotstein LE, et al: Classification of mandibular defects. Plast Reconstr Surg 1993; 92: 1266-1275. 
7- Reece GP, Kroll SS, Schusterman MA: Free flap techniques for mandibular reconstruction. In: Reconstructive plastic surgery for cancer. Kroll SS (Editor); St. Louis: Mosby (Publisher); 1996; p. 94-106.

8- Trost O, Duvernay A, Parmentier J, Malka G: Reconstruction of bony mandibular and maxillary defects with one single transfer of a free fibular osteocutaneous flap. J Plast Reconstr Aesthet Surg 2008; 61: 1385.

9- Eppley BL: Nonvascularized Methods of mandible reconstruction. Operative Techniques in Plastic and Reconstructive Surgery 1996; 3(4): 226-232.

10-Takushima A, Harii K, Asato H, et al: Choice of osseous and osteocutaneous flaps for mandibular reconstruction. Int J Clin Oncol 2005; 10: 234-242.

11-Burguera M, Fernandez JR, Viano JM: A 3d-Fem highest stress lines in mandible fractures by elastic impact. Computer Methods in Biomechanics and Biomedical Engineering 2000; 3: 273-285.

12-Irish JC, Gullane PJ, Gilbert RW, et al: Primary mandibular reconstruction with the titanium hollow screw reconstruction plate: Evaluation of 51 cases. Plast Reconstr Surg 1995; 96: 93-99.

13-Shibahara T, Noma H, Furuya Y, et al: Fracture of mandibular reconstruction plates used after tumor resection. J Oral Maxillofac Surg 2002; 60: 182-185.

14-Hidalgo DA, Pusic AL: Free-flap mandibular reconstruction: A 10-year follow-up study. Plast Reconstr Surg 2002; 110: 438-449.

15-Hidalgo DA, Rekow A: A review of 60 consecutive fibula free flap mandible reconstructions. Plast Reconstr Surg 1995; 96: 585 .

16-Cordey J, Borgeaud M, Perren SM: Force transfer between the plate and the bone: Relative importance of the bending stiffness of the screws and the friction between plate and bone. Injury 2000; 31 (3 Suppl): Summary.

17-Hidalgo DA: Refinements in mandible reconstruction. Operative Techniques in Plastic and Reconstructive Surgery 1996; 3(4): 257-263.
18-Boyd JB, Mulholland RS, Davidson J,et al: The free flap and plate in oromandibular reconstruction: Long-term review and indications. Plast Reconstr Surg 1995; 95: 1018.

19-Shenaq SM, Klebuc MJA, Shenaq J, Safak T: Mandibular reconstruction with the iliac crest, composite, microsurgical free flap. Operative Techniques in Plastic and Reconstructive Surgery 1996; 3(4): 289294.

20-Hidalgo DA: Aesthetic improvements in free-flap mandible reconstruction. Plast Reconstr Surg 1991; 88: 574.

21-Seikaly H, Maharaj M, Rieger J, et al: Functional outcomes after primary mandibular resection and reconstruction with the fibular free flap. J Otolaryngol 2005; 34: 25-28.

22-Serletti JM, Coniglio JU, Tavin E, Bakamjian VY: Simultaneous transfer of free fibula and radial forearm flaps for complex oromandibular reconstruction. $J$ Reconstr Microsurg 1998; 14: 297.

23-Boyd JB, Rosen I, Rotstein L, et al: The iliac crest and the radial forearm flap in vascularized oromandibular reconstruction. Am J Surg 1990; 159: 301.

24-Wei FC, Celik N, Chen HC, Cheng MH, Huang WC: Combined anterolateral thigh flap and vascularized fibula osteoseptocutaneous flap in reconstruction of extensive composite mandibular defects. Plast Reconstr Surg 2002; 109: 45.

25-Punjabi AP, Thaller SR: Late complications of mandibular fractures. Operative Techniques in Plastic and Reconstructive Surgery 1998; 5(3): 266-274.

26-Taylor GI, Corlett RJ: Microvascular free transfer of a compound deep circumflex groin and iliac crest flap to the mandible. In: Grabb's encyclopedia of flaps. Strauch B, Vasconez LO, Hall-Findlay EJ (Editors); Boston: Little Brown (Publisher); 1990; p.589-599.

27-Hidalgo DA: Fibula free flap: A new method of mandible reconstruction. Plast Reconstr Surg 1989; 84: 71. 
28-Laure B, Sury F, Martin T, et al: Reconstruction of bony mandibular and maxillary defects with one single transfer of a free fibula osteocutaneous flap. J Plast Reconstr Aesthet Surg 2008; 61: 200-203.

29-Maciejewski A, Szymczyk C: Fibula free flap for mandible reconstruction: Analysis of 30 consecutive cases and quality of life evaluation. J Reconstr Microsurg 2007; 23: 1-10.

30-Peled M, El-Naaj IA, Lipin Y, et al: The use of free fibular flap for functional mandibular reconstruction. J Oral Maxillofac Surg 2005; 63: 220-224.

31-Zide MF, Ducic Y: Fibula microvascular free tissue reconstruction of the severely comminuted atrophic mandible fracture: Case report. J Craniomaxillofac Surg 2003; 31: 296-298.

32-Alpert B: Management of the complications of mandibular fracture treatment. Operative Techniques in Plastic and Reconstructive Surgery 1998; 5(4): 325-333.

33-Coletti D, Ord RA: Treatment rationale for pathological fractures of the mandible: A series of 44 fractures. Int J Oral Maxillofac Surg 2008; 37: 215-222.

34-Blackwell KE, Buchbinder D, Urken ML: Lateral mandibular reconstruction using soft-tissue free flaps and plates. Arch Otolaryngol Head Neck Surg 1996; 122: 672-678.

35-Deleyiannis FW, Rogers C, Lee E, et al: Reconstruction of the lateral mandibulectomy defect: Management based on prognosis and location and volume of soft tissue resection. Laryngoscope 2006; 116: 2071-2080.

36-Nicoletti G, Soutar DS, Jackson M, Wrench A, Robertson G, Robertson C: Chewing and swallowing after surgical treatment for oral cancer: Functional evaluation in 196 selected cases. Plast Reconstr Surg 2004; 114(2): 329-338.
37-Nicoletti G, Soutar DS, Jackson M, Wrench, A, Robertson G, Robertson C: Objective assessment of speech after surgical treatment for oral cancer: Experience from 196 selected cases. Plast Reconstr Surg 2004; 113: 114.

38-Wei FC, Celik N, Yang WG, Chen IH, Chang YM, Chen HC: Complications after reconstruction by plate and soft-tissue free flap in composite mandibular defects and secondary salvage reconstruction with osteocutaneous flap. Plast Reconstr Surg 2003; 112(1).

39-Labbé D, Nicolas J, Kaluzinski E, et al: Gunshot wounds: Reconstruction of the lower face by osteogenic distraction. Plast Reconstr Surg 2005; 116: 1596-1603. 40-Celik N, Wei F C, Chen H C, et al: Osteoradionecrosis of the mandible after oromandibular cancer surgery. Plast Reconstr Surg 2002; 109: 1875. 41-Ioannides C, Fossion E, Boecke W, Hermans B, Jacobs D: Surgical management of the osteoradionecrotic mandible with free vascularised composite flaps. J Craniomaxillofac Surg 1994; 22: 330-334.

42-Wang Z, Qiu W, Mendenhall WM: Influence of radiation therapy on reconstructive flaps after radical resection of head and neck cancer. Int J Oral Maxillofac Surg 2003; 32: 35-38. 43-Wang ZH, Zhang ZY, Mendenhall WM: Postoperative radiotherapy after titanium plate mandibular reconstruction for oral cavity cancer. American Journal of Clinical Oncology 2005; 28(5). 